\title{
Does On-Pump Beating Heart Endoaneurysmorrhaphy Have Advantages over Linear Aneurysmectomy on Arrested Heart in the Short Term?
}

\author{
Onursal Bugra, $\mathbf{M D},{ }^{1}$ Bahadir Daglar, $\mathrm{MD}^{2}$ \\ ${ }^{1}$ Department of Cardiovascular Surgery, Medical Faculty of Balikesir University, Balikesir, Turkey; \\ ${ }^{2}$ Department of Cardiovascular Surgery, Avrupa Safak Hospital, Gaziosmanpasa, Istanbul, Turkey
}

\section{ABSTRACT}

Background: It is still controversial which left ventricular aneurysm repair technique is optimal in terms of early and late results. This study aimed to compare early postoperative outcomes for 2 surgical treatments of postinfarction left ventricular aneurysm: linear repair technique on arrested heart versus endoaneurysmorrhaphy repair with patch plasty on beating heart.

Methods: Prospectively collected data from 16 consecutive patients who underwent endoaneurysmorrhaphy repair with patch plasty on beating heart (the technique we have preferred since 2008) were compared with data from a retrospective series of 10 patients who underwent linear repair on arrested heart (the technique we preferred until 2008). All operations were performed under elective conditions.

Results: Baseline characteristics of the 2 groups were similar. Complete revascularization for all diseased vessels was achieved in all patients. Durations of cross clamping, cardiopulmonary bypass, intensive care stay, and hospital stay were longer, and postoperative ejection fraction was lower, in the linear repair group compared with the endoaneurysmorrhaphy group $(P<.05$ for all). Early mortality occurred in 1 patient $(3.8 \%)$ in the linear repair group.

Conclusion: Endoaneurysmorrhaphy repair with patch plasty on beating heart seems to offer advantages over the linear repair technique on arrested heart in the treatment of left ventricular aneurysms. Future large-scale prospective studies with longer follow-up are warranted to draw firm conclusions.

\section{INTRODUCTION}

Development of left ventricular (LV) aneurysm, a common and important complication of acute transmural myocardial infarction, is associated with the development of heart failure and poor survival. LV aneurysms generally develop as a consequence of extensive anterior myocardial infarctions and

Received August 6, 2020; received in revised form September 10, 2020; accepted September 10, 2020.

Correspondence: Dr. Onursal Bugra, Balikesir University Tip Fakultesi, Kalp Damar Cerrabisi Klinigi, Cagis Yerleskesi, 10145 Balikesir, Turkey; +90 532 4774005 (e-mail: onursalbugra@gmail.com). involve the anteroapical wall of the left ventricle. Surgical repair has a quite variable operative mortality rate of $2 \%$ to $42 \%$, with a mean of $15 \%$ [Campagnucci 2006].

Surgical repair of $\mathrm{LV}$ aneurysm was first reported by Likoff et al. [1955], and Cooley et al. [1958] were the first to operate with cardiopulmonary bypass (CBP). Surgical techniques evolved over decades, and the techniques incorporating patch plasty in an attempt to better restore LV geometry were defined by Cooley [1989], Jatene [1985], and Dor [1989] since then. Alternatively, performing the repair on a beating heart has the potential to avoid the effects of myocardial ischemia, and ventricular aneurysm repair on a beating heart has been reported with promising results [Wang 2012]. However, it is still controversial which technique is optimal in terms of early and late results.

This study aimed to compare early postoperative outcomes of the 2 techniques - aneurysmectomy and linear repair technique on arrested heart versus endoaneurysmorrhaphy repair with patch plasty on beating heart-for the surgical treatment of postinfarction left ventricular aneurysm.

\section{METHODS}

\section{Patients}

A search of the hospital database revealed that $26(3.6 \%)$ of a total 720 coronary artery bypass surgery patients underwent a concomitant procedure for the repair of postinfarction left ventricular aneurysm between October 2006 and December 2015. Prospectively collected data from 16 consecutive patients $(61.5 \%$ of this study's cohort) in whom we performed the aneurysm repair using on-pump beating heart endoaneurysmorrhaphy (the technique we have preferred since 2008) were compared with data from a retrospective series of 10 patients ( $31.5 \%$ of this study's cohort) who were treated with conventional linear aneurysmectomy (the technique we preferred until 2008). Left ventricular aneurysm diagnosis was based on demonstration of a dyskinetic aneurysm in echocardiography. Patients with symptoms of cardiac decompensation were appropriately treated with diuretics and vasoactive drugs during the preoperative period. The study was approved by the local ethics committee (AIBU 2011/85). Prospectively included patients gave informed consent for inclusion. 


\section{Operation}

\section{Cardiopulmonary Bypass}

All operations were performed under elective conditions; none of the operations were for emergency indications such as aneurysm rupture. The operations were performed by the same surgical team with the participation of 2 experienced surgeons. After midline sternotomy incision and pericardiotomy, care was taken to avoid manipulating the aneurysm before cross clamping the aorta, to prevent possible thrombus embolization. After aortic cross clamping, a left heart venting cannula was placed via the right superior pulmonary vein but not advanced into the left ventricle. Nasopharyngeal temperature was lowered to $32^{\circ} \mathrm{C}$. Myocardial protection was achieved with intermittent doses (every 20 minutes) of antegrade isothermic blood cardioplegia combined with retrograde continuous infusion.

\section{On-Pump Beating Heart Endoaneurysmorrhaphy}

In the on-pump beating heart endoaneurysmorrhaphy group, distal coronary anastomoses, mitral valve replacement, or both were done under CBP with aortic cross-clamp. Crossclamp was then removed, and the proximal anastomoses were made using a side clamp. Next, the aneurysm repaired on beating heart. The aneurysm was opened beginning lateral to the apex of the left ventricle and directing superiorly,

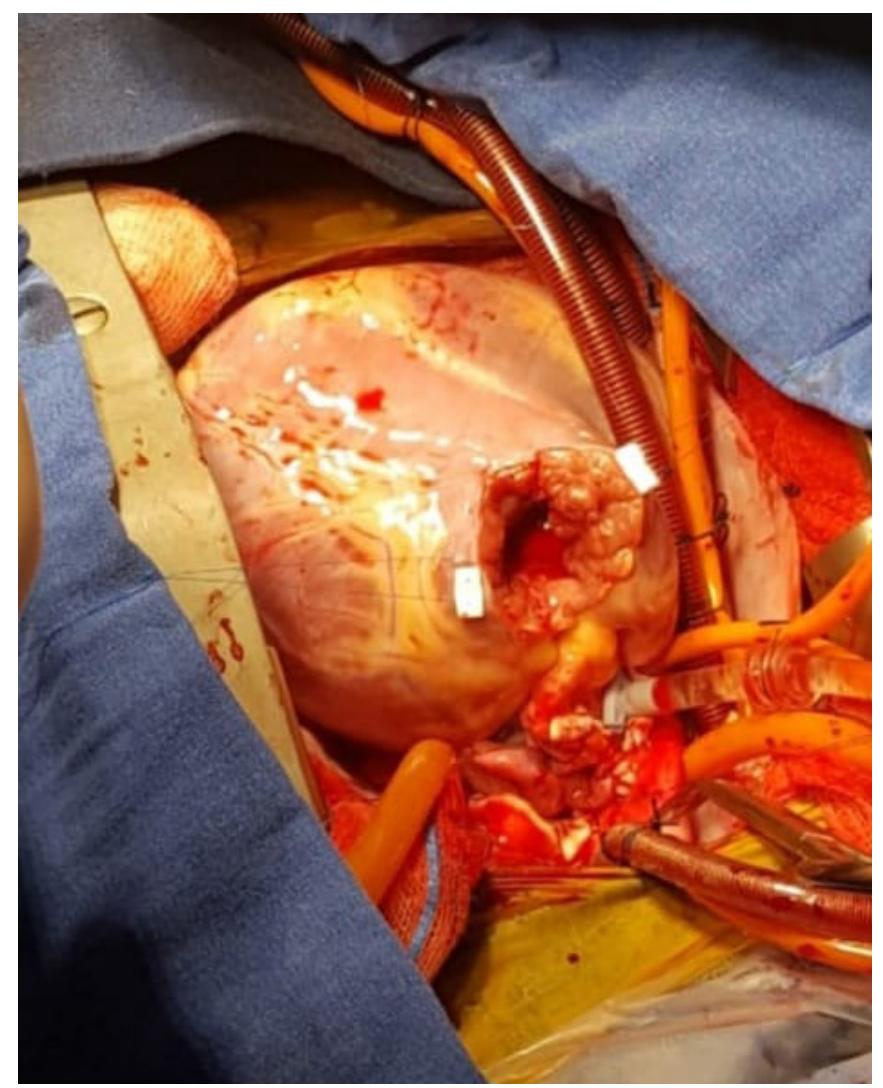

Figure. The appearance of the apex after opening the aneurysm sac and removing excess aneurysm tissue during on-pump beating heart endoaneurysmorrhaphy. parallel and 1 to $2 \mathrm{~cm}$ lateral to the left anterior descending artery. Stay sutures were placed to enhance visualization and lift the apex upward, and the ventricular cavity and papillary muscle attachments were inspected for thrombus. The Figure shows the appearance of the apex after opening the aneurysm sac and removing excess aneurysm tissue. The sucker end of an additional left heart venting cannula was advanced through the left ventricular cavity, and the cavity and anatomic structures were meticulously cleared of thrombus by direct removal. The suturing zone between the scarred region and the normal myocardium was identified. The pericardial patch freshly harvested from the patient for circumferential endoaneurysmorrhaphy repair was attached to the suturing zone with continuous sutures. Just before tying both ends of the sutures, the left heart vent that had been placed through aneurysmectomy was stopped to allow the ventricle to fill with blood, and deairing was achieved through a small aperture left between the patch and the suturing border. The excess part of the aneurysm sac was resected, and the remaining aneurysm wall was closed over the patch with overlapping sutures.

\section{Linear Aneurysmectomy Procedure}

In the linear aneurysmectomy group, aneurysm repair and all other additional procedures were done under CBP. After coronary anastomoses, mitral valve replacement, or both, the aneurysm sac was opened using the same technique as above and resected. Leaving the scarred region outside, 2 edges of the viable myocardial edges were reapproximated with single $\mathrm{U}$ sutures that were reinforced with 2 corresponding Teflon felt strips. The suture line was further strengthened by an additional continuous suture line overlapping the previous suture line. The cross clamp was removed, and the heart was filled via right superior pulmonary vein cannula and deaired via dual lumen aortic root cannula.

\section{Statistical Analysis}

All statistical analyses were performed using Statistical Package for Social Sciences version 11.0 (SPSS, Chicago, IL). Shapiro-Wilk test and graphical methods including histogram, stem-and-leaf plot, box plot, probability-probability (P-P) plot, and quantile-quantile plot (Q-Q) were used to test and judge for normality. Normally distributed continuous data presented as mean \pm standard deviation were compared using Student's $t$ test. Non-normally distributed data presented as median (range) were compared using Mann-Whitney $U$ test. Categorical data presented as $\mathrm{n}(\%)$ were compared using $\chi^{2}$ test or Fisher's exact test. For $2 \times 2$ contingency tables, $\chi^{2}$ test was used when no cell had expected count $<5$; otherwise, Fisher's exact test was used. A $P$ value $<.05$ was considered statistically significant.

\section{RESULTS}

Complete revascularization of all diseased vessels, including left anterior descending artery, was achieved in all patients. Left anterior descending artery revascularization was made using left internal mammary artery in all patients. 
Table 1. Baseline and Intraoperative Characteristics*

\begin{tabular}{|c|c|c|c|}
\hline Characteristic & Linear Aneurysmectomy $(n=10)$ & Endoaneurysmorrhaphy $(n=16)$ & $P$ value \\
\hline Age, y & $66.7 \pm 6.7$ & $68.7 \pm 6.9$ & .35 \\
\hline Hypertension & $3(30.0)$ & $6(37.5)$ & .25 \\
\hline Diabetes & $3(30.0)$ & $5(31.3)$ & .94 \\
\hline EF & 35.0 (25 to 40$)$ & $35.0(25$ to 45$)$ & .57 \\
\hline LVEDD (mm) & $60(58$ to 61$)$ & 61 (59 to 63$)$ & .45 \\
\hline LVESD (mm) & 54 (51 to 55$)$ & $55(52$ to 56$)$ & .33 \\
\hline Aneurysm size $(\mathrm{cm})$ & 5 (4 to 8$)$ & 5 (4 to 7 ) & .67 \\
\hline \multicolumn{4}{|l|}{ Operative characteristics } \\
\hline Cross-clamp time (min) & $103.0 \pm 27.8$ & $51.2 \pm 26.6$ & $<.001$ \\
\hline
\end{tabular}

*Data are mean \pm standard deviation, median (range), or $\mathrm{n}(\%)$.

EF indicates ejection fraction; LVEDD, left ventricular end-diastolic diameter; LVESD, left ventricular end-systolic diameter.

Table 2. Postoperative Characteristics*

\begin{tabular}{lccc}
\hline Characteristic & Linear Aneurysmectomy $(\mathrm{n}=10)$ & Endoaneurysmorrhaphy $(\mathrm{n}=16)$ \\
\hline Extubation time $(\mathrm{h})$ & $8(4$ to 30$)$ & $6(5$ to 20$)$ & $1(6.3)$ \\
Low cardiac output syndrome & $1(10.0)$ & $5(31.3)$ & .35 \\
Low-dose inotropic use & $3(30.0)$ & $3(18.8)$ & .50 \\
High-dose inotropic use & $2(20.0)$ & 0 & .85 \\
Reoperation because of bleeding & $1(10.0)$ & $4(25.0)$ \\
Mechanical support & $1(10.0)$ & $4(2$ to 7$)$ \\
Atrial fibrillation & $3(30.0)$ & $11(7$ to 18$)$ \\
ICU stay $(d)$ & $6(2$ to 12$)$ & 0 & .94 \\
Hospital stay $(d)$ & $16(7$ to 23$)$ & .39 \\
Mortality & $1(10.0)$ & .39 \\
EF & $40(35$ to 40$)$ & $52.5(35$ to 55$)$ \\
LVEDD $(\mathrm{mm})$ & $54(51$ to 55$)$ & $53(52$ to 56$)$ \\
LVESS $(\mathrm{mm})$ & $47(35$ to 40$)$ & $46(35$ to 40$)$ \\
\hline
\end{tabular}

*Data are median (range) or $\mathrm{n}(\%)$.

EF indicates ejection fraction; LVEDD, left ventricular end-diastolic diameter; LVESD, left ventricular end-systolic diameter.

Table 1 shows baseline and intraoperative characteristics. The 2 groups did not differ in terms of preoperative baseline characteristics, number of coronary grafts used, or distribution of mitral valve repair $(P>.05$ for all). However, CBP time and cross-clamp time were longer in the linear aneurysmectomy group $(P<.001$ for both).
Table 2 shows early postoperative outcomes for the 2 groups. The groups did not differ regarding extubation time or the frequency of low cardiac output syndrome, low- or high-dose inotropic use, reoperation because of bleeding, mechanical support, atrial fibrillation, or early postoperative mortality $(P>.05$ for all). In contrast, durations of intensive 
care unit (ICU) stay $(P=.04)$ and hospital stay $(P=.03)$ were longer, and postoperative ejection fraction was lower $(P=.04)$, in the linear aneurysmectomy group compared with the endoaneurysmorrhaphy group. The 2 groups did not differ regarding $\mathrm{LV}$ end-diastolic diameter or $\mathrm{LV}$ end-systolic diameter $(P>.05$ for both).

Early mortality occurred in 1 patient. This patient was from the linear aneurysmectomy group and had additional mitral valve repair. Postoperatively, the patient had serious ventricular arrhythmia episodes and developed subsequent low cardiac output syndrome. He failed to improve despite early treatment with intra-aortic balloon pump (IABP) and intensive use of vasoactive drugs, and he could not be weaned from mechanical ventilation after the operation. Because respiratory parameters did not improve despite high fraction of inspired oxygen (FiO2) levels, extracorporeal membrane oxygenation was initiated on the third postoperative day. The patient died of multiorgan failure on the seventh postoperative day.

\section{DISCUSSION}

The findings of this study, comparing the short-term outcomes of patients who underwent circumferential endoaneurysmorrhaphy repair on a beating heart and patients who underwent classic linear repair on arrested heart for the treatment of left ventricular aneurysm, are in favor of the former technique, with shortened stay and operation times and better ejection fraction.

The most important disadvantages of classic linear repair are the risks of constituting a small residual left ventricular cavity and altering the normal geometry of the ventricle. Preserving the normal geometrical shape of the left ventricle is one of the most important advantages of the endoventricular repair technique. Closure of the aneurysm sac over the patch enhances the durability of the repair against rupture and diminishes wall stress.

In our institution, left ventricular aneurysm repair operations were performed using the linear repair technique on arrested heart between 2007 and 2008. Since 2008, we have adopted on-pump endoventricular repair on beating heart to shorten the duration of aortic cross clamping, thus preventing the loss of cardiac functional reserve, particularly in those patients with poor left ventricular function. Moreover, the scarred region becomes more distinguishable on a beating heart, facilitating the decent and confident removal of aneurysm tissue. The systemic inflammatory response is known to be diminished when surgery is performed on a beating heart. Maxey et al. [2003] reported shorter ischemia time when left ventricular aneurysm repair was performed on a beating heart, although no additional benefits were observed in that study. Similarly, cross-clamping time was significantly shorter in the endoventricular repair group in our study, which in our opinion offers an advantage.

Initial reports on endovascular circular patch plasty (Dor procedure) for left ventricular aneurysm repair were promising [Sartipy 2005, Dor 1989], which was followed by several studies comparing this technique or modifications with the linear repair technique, with inconsistent results reporting improved outcomes with the Dor procedure or satisfactory outcomes with both procedures [Chen 2010, Erbasan 2009, Chen 2009, Mukaddirov 2008, Parolari 2007, Baev 2006, Antunes 2005, Lundblad 2004, Benetis 2004, Tavakoli 2002]. For example, in line with our findings, Dor et al. [2004] reported an increase in ejection fraction during follow-up of patients who received endoventricular repair. Lundbald et al. [2004] reported that advanced age, 3-vessel disease, and linear repair technique were associated with increased mortality in patients who underwent left ventricular aneurysm repair. However, several studies reported no important significant differences between the 2 techniques in terms of outcomes [Antunes 2005, Erbasan 2009, Mukaddirov 2008, Tavakoli 2002].

Similar to our study, recent studies mostly provide evidence in favor of the patch plasty repair technique. A recent study from Turkey compared circular patch plasty and linear repair techniques for left ventricular aneurysms, not performed on beating heart [Kaya 2018]. IABP requirement and postoperative arrythmia were more common in the circular patch plasty group and linear repair group, respectively; however, the 2 groups did not differ in terms of early mortality or other early postoperative outcomes. At 1 year, patients who underwent circular patch plasty had more improvement in $\mathrm{LV}$ systolic function. A 2016 study from Hungary also compared endoventricular patch plasty and linear suture techniques and found that the former was associated with less perioperative mortality, better 5-year survival, and better improvements in left ventricular ejection fraction (LVEF) and New York Heart Association (NYHA) functional class [Balau 2018]. In the study by Chen et al. [2012] comparing patch remodeling with linear technique, the former was associated with better outcomes in terms of LVEF and LV dimensions and volumes, although in-hospital mortality did not differ.

The study by Wang et al. [2012] compared linear repair versus endoventricular circular patch plasty techniques as well as beating heart versus cardioplegia techniques. Linear and patch repair groups did not differ regarding early mortality and survival up to 2 years. In contrast, beating heart technique resulted in a $27 \%$ reduction in cardiac troponin I levels and improved perioperative survival compared with the cardioplegia group [Wang 2012].

The patch plasty technique has also been compared with the off-pump linear plication technique. In a study by Wei et al. [2019], off-pump linear plication was compared with onpump endoventricular patch plasty in $\mathrm{LV}$ aneurysms in terms of early and long-term outcomes. No significant difference was found between the groups in terms of cardiac function at discharge and long-term survival; however, fewer patients suffered low cardiac output syndrome and required IABP, and recovery times were shorter, in the off-pump linear plication group [Wei 2019]. The authors recommended the simple linear plication technique, particularly for high-risk patients. In that study, patients in the linear plication groups seemed to have the advantages of the off-pump technique, avoiding the morbidity associated with CBP. In contrast, Huang et al. [2012] did not find any difference between off-pump anteroapical aneurysm plication and patch modeling repair in terms 
of early mortality, IABP and inotropic requirement, $\leq 5$-year survival, or functional class improvement.

This study has some limitations, including retrospective design, a small number of patients from a single center, and short duration of follow-up. The 2 techniques were adopted during different time periods in this study, which may be considered a potential source of bias. Likewise, meta-analysis has shown that geometric reconstruction has an advantage over linear technique when there is difference in the time frame that the 2 techniques were adopted (i.e., linear repair adopted earlier and geometric construction adopted later) [Parolari 2007]. However, when the 2 approaches were adopted during the same time period there was no difference, which may reflect the effect of learning curve over time [Parolari 2007]. In this study, the technique adopted later (on-pump beating heart endoaneurysmorrhaphy) is 50 minutes faster than the earlier technique when mean CBP time and cross-clamp time are considered. In our opinion, this may be attributed to current advances in cardiac surgery techniques as well as the increased overall experience of the surgeons and the surgical team who performed the operations.

\section{CONCLUSION}

On-pump beating heart endoaneurysmorrhaphy using patch seems to have several advantages over classic aneurysmectomy with linear repair on arrested heart in the treatment of left ventricular aneurysms. The advantages may be due partly to the benefits of beating heart technique and partly to better restoration of ventricular geometry using a patch. These results need to be tested in large studies to draw firm conclusions.

\section{REFERENCES}

Antunes PE, Silva R, Ferrao de Oliveira J, Antunes MJ. 2005. Left ventricular aneurysms: Early and long-term results of two types of repair. Eur J Cardiothorac Surg 27:210-215.

Baev B, Petkov D, Nikolov D, Nachev G. 2006. [Surgical treatment of left ventricular aneurysms-Midterm results with two types of repair-Linear resection and endoventricular repair]. Khirurgiia (Sofiia) (4-5):15-18.

Balau R, Deac R, Kovacs J, et al. 2018. [Surgical ventricular reconstruction for ischemic left ventricular aneurysm. Early and medium-term outcomes for two surgical techniques]. Orv Hetil 159:2167-2174.

Benetis R, Vaskelyte J, Raugeliene R, Ereminiene E, Jankauskiene L. 2004. [Early complications and changes of left ventricular geometry and volume following two types of ventricular reconstruction: Compression of scar zone and modified Dor aneurysmectomy]. Medicina (Kaunas) 40(suppl 1):35-38.

Campagnucci V, Rivetti L, Pinto A, Matheus S. 2006. Left ventricular aneurysmectomy with continuous beating heart: early results. Braz J Cardiovasc Surg 21:55-61.

Chen WY, Wu FY, Shih CC, Lai ST, Hsu CP. 2009. Left ventricular aneurysm repair: A comparison of linear versus patch remodeling. J Chin Med Assoc 72:414-421.
Chen X, Qiu ZB, Xu M, et al. 2010. [Surgical treatment of post-infarction left ventricular aneurysm: Clinical analysis]. Zhonghua Yi Xue Za Zhi 90:3403-3406.

Chen X, Qiu ZB, Xu M, Liu LL, Jiang YS, Wang LM. 2012. Surgery for left ventricular aneurysm after myocardial infarction: Techniques selection and results assessment. Chin Med J (Engl) 125:4373-4379.

Cooley DA. 1989. Ventricular endoaneurysmorrhaphy: A simplified repair for extensive postinfarction aneurysm. J Card Surg 4:200-205.

Cooley DA, Collins HA, Morris GC, Jr., Chapman DW. 1958. Ventricular aneurysm after myocardial infarction; surgical excision with use of temporary cardiopulmonary bypass. J Am Med Assoc 167:557-560.

Dor V, Saab M, Coste P, Kornaszewska M, Montiglio F. 1989. Left ventricular aneurysm: A new surgical approach. Thorac Cardiovasc Surg 37:11-19.

Dor V, Sabatier M, Montiglio F, Civaia F, DiDonato M. 2004. Endoventricular patch reconstruction of ischemic failing ventricle. A single center with 20 years experience. Advantages of magnetic resonance imaging assessment. Heart Fail Rev 9:269-286.

Erbasan O, Turkay C, Mete A, et al. 2009. Surgical treatment of left ventricular aneurysms: A comparison of long-term follow-up of left ventricular function for classic aneurysmectomy and endoaneurysmorrhaphy techniques. Heart Surg Forum 12:E272-E278.

Huang XS, Gu CX, Yang JF, et al. 2012. Off-pump anteroapical aneurysm plication for left ventricular post-infarction aneurysm: long-term results. Chin Med J (Engl) 125:3228-3235.

Jatene AD. 1985. Left ventricular aneurysmectomy. Resection or reconstruction. J Thorac Cardiovasc Surg 89:321-331.

Kaya U, Colak A, Becit N, Ceviz M, Kocak H. 2018. Application of circular patch plasty (Dor procedure) or linear repair techniques in the treatment of left ventricular aneurysms. Braz J Cardiovasc Surg 33:135-142.

Likoff W, Bailey CP. 1955. Ventriculoplasty: Excision of myocardial aneurysm; report of a successful case. J Am Med Assoc 158:915-920.

Lundblad R, Abdelnoor M, Svennevig JL. 2004. Surgery for left ventricular aneurysm: early and late survival after simple linear repair and endoventricular patch plasty. J Thorac Cardiovasc Surg 128:449-456.

Maxey TS, Reece TB, Ellman PI, Kern JA, Tribble CG, Kron IL. 2003. The beating heart approach is not necessary for the Dor procedure. Ann Thorac Surg 76:1571-1575.

Mukaddirov M, Frapier JM, Demaria RG, Albat B. 2008. Surgical treatment of postinfarction anterior left ventricular aneurysms: Linear vs. patch plasty repair. Interact Cardiovasc Thorac Surg 7:256-261.

Parolari A, Naliato M, Loardi C, et al. 2007. Surgery of left ventricular aneurysm: A meta-analysis of early outcomes following different reconstruction techniques. Ann Thorac Surg 83:2009-2016.

Sartipy U, Albage A, Lindblom D. 2005. The Dor procedure for left ventricular reconstruction. Ten-year clinical experience. Eur J Cardiothorac Surg 27:1005-1010.

Tavakoli R, Bettex D, Weber A, et al. 2002. Repair of postinfarction dyskinetic LV aneurysm with either linear or patch technique. Eur J Cardiothorac Surg 22:129-134.

Wang X, He X, Mei Y, et al. 2012. Early results after surgical treatment of left ventricular aneurysm. J Cardiothorac Surg 7:126.

Wei H, Chai S, Liu C, Huang X, Gu C. 2019. Left ventricular aneurysm repair: Off-pump linear plication versus on-pump patch plasty. Braz J Cardiovasc Surg 34:187-193. 